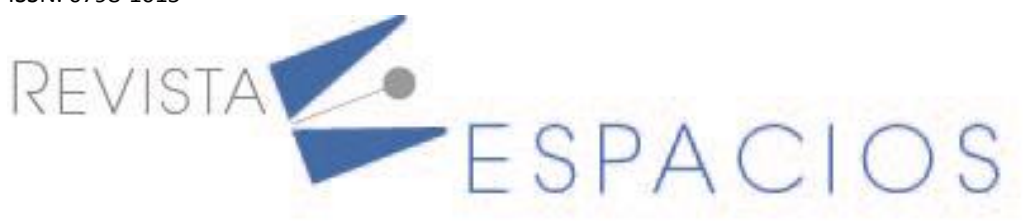

Vol. 41 (43) $2020 \cdot$ Art. 10

\title{
Socionic models of a person and their application in aviation
}

\author{
Modelos sociónicos de una persona y su aplicación en la aviación
}

\author{
ARINICHEVA, Olga V. ${ }^{1}$ \\ LEBEDEVA, Natalia A. ${ }^{2}$ \\ MALISHEVSKII, Aleksei V. ${ }^{3}$
}

\begin{abstract}
The article contains mathematical models of a person's socionics characteristics based on fuzzy set theory. The practical application of the proposed models is focused on assessing professional aptitude of operators who have to process massive flows of information at a forced pace (for example, aircraft pilots or air traffic controllers).

Keywords: typology, information metabolism, socionics, fuzzy sets, socionics models

Resumen

El artículo contiene modelos matemáticos de las características sociónicas de una persona basadas en la teoría de conjuntos difusos. La aplicación práctica de los modelos propuestos se centra en evaluar la aptitud profesional de los operadores que tienen que procesar flujos masivos de información a un ritmo forzado (por ejemplo, pilotos de aeronaves o controladores de tráfico aéreo).

Palabras clave: tipología, metabolismo de la información, sociónica, conjuntos difusos, modelos sociónicos.
\end{abstract}

\section{Introduction}

The theory of psychological types developed by the Swiss psychiatrist Carl Gustav Jung (1971) combined with the idea of such a psychological phenomenon as information metabolism (IM) proposed by the Polish psychologist Antoni Kępiński (2014) gave rise to an independent direction in typology which is called socionics (Augustinavičiūtè, 2016; Karpenko \& Bukalov, 2014; Filatova, 1999; Bukalov, 2009; Reinin, 2009; Gulenko, 2007; Leichenko et al., 2006; Bukalov, 2003). This direction was founded by the Lithuanian researcher Aušra Augustinavičiūte and it differs significantly from the trend popular in the USA and Western Europe. This trend is based on Jung's theory (Jung, 1971), works by American psychologists Katharine Cook Briggs and Isabel Briggs Myers (Myers \& McCaulley, 1985; Myers \& Myers, 1995), as well as David Keirsey's works (Keirsey, 1998). The differences between these directions are discussed in detail in (Bukalov, 2003; Leichenko et al., 2006; Arinicheva

\footnotetext{
1 Ph.D. of engineering sciences, associate professor at the department of Flight Operations and Flight Safety in Civil Aviation, Saint Petersburg State University of Civil Aviation, 196210, 38 Pilotov st., Saint Petersburg, Russia. 2067535@mail.ru

2 Ph.D. of historical sciences, head of the department of Language Training, Saint Petersburg State University of Civil Aviation, 196210,38 Pilotov st., Saint Petersburg, Russia. lebedevanatali@inbox.ru

${ }^{3}$ Ph.D. of engineering sciences, associate professor at the department of Flight Operations and Flight Safety in Civil Aviation, Saint Petersburg State University of Civil Aviation, 196210, 38 Pilotov st., Saint Petersburg, Russia. 9909395@bk.ru
} 
\& Malishevskii, 2017; Bukalov, 2017) and are most clearly and concisely formulated in the article by R. Blutner and E. Hochnadel (2010).

As the authors of this article noted in their works (Malishevskii et al., 2015a; Arinicheva et al., 2020), "traditional" socionics (Augustinavičiūtè, 2016; Bukalov, 2009; Filatova, 1999) believes that each person has his or her specific type of information metabolism (TIM). A person's TIM is the way how this person perceives, processes, and transmits information in the broadest sense of the term. At the level of ordinary common sense, it is clear that the TIM which an aviation professional, in particular a pilot or air traffic control controller (ATC) has, cannot but affect his or her success at work, i.e. TIMs should be considered to be qualities important in a work environment in aviation (all TIMs and their correspondence to personality types are given in table 1).

Table 1

A rough correspondence between the types of information metabolism

in socionics and the personality types according to K. Briggs and I. Myers

\begin{tabular}{|l|c|c|c|}
\hline \multicolumn{2}{|c|}{$\begin{array}{c}\text { Types of information metabolism } \\
\text { in socionics }\end{array}$} & $\begin{array}{c}\text { Personality types according to } \\
\text { K. Briggs and I. Myers }\end{array}$ \\
\hline Intuitive Logical Extravert & ILE & 1 & ENTP \\
\hline Sensory Ethical Introvert & SEI & 2 & ISFP \\
\hline Ethical Sensory Extravert & ESE & 3 & ESFJ \\
\hline Logical Intuitive Introvert & LII & 4 & INTJ \\
\hline Ethical Intuitive Extravert & EIE & 5 & ENFJ \\
\hline Logical Sensory Introvert & LSI & 6 & ISTJ \\
\hline Sensory Logical Extravert & SLE & 7 & ESTP \\
\hline Intuitive Ethical Introvert & IEI & 8 & INFP \\
\hline Logical Intuitive Extravert & LIE & 9 & ENTJ \\
\hline Ethical Sensory Introvert & ESI & 10 & ISFJ \\
\hline Sensory Ethical Extravert & SEE & 11 & ESFP \\
\hline Intuitive Logical Introvert & ILI & 12 & INTP \\
\hline Logical Sensory Extravert & LSE & 13 & ESTJ \\
\hline Ethical Intuitive Introvert & EII & 14 & ENFJ \\
\hline Intuitive Ethical Extravert & IEE & 15 & ISTP \\
\hline Sensory Logical Introvert & SLI & 16 & Sensing / Intuition (S/N) \\
\hline \multicolumn{2}{|c|}{ Psychological dichotomies } \\
\hline Extraversion / Introversion (E/I) & Extraversion / Introversion (E/I) \\
\hline Logic / Ethics (L/E) & & Judgment / Perception (J/P) \\
\hline Sensing / Intuition (S/I) & & \\
\hline \multicolumn{2}{|c|}{ Rationality / Irrationality (R/I) } & \\
\hline
\end{tabular}

Source: Arinicheva et al. (2020), Leichenko et al. (2006)

However, judging by works devoted to socionics, for example (Karpenko \& Bukalov, 2014; Filatova, 1999), many socionics professionals are concerned about the fact that the 16 TIMs covered by the classical theory describe the huge variety of information metabolism processes in a too simplified and primitive way. E. S. Filatova writes the following in her book: "Among representatives of the same type, there are people who are very different from each other. This means that 16 is an intermediate rather than the final number. A psychological type could be described much more accurately if each of the 16 types were divided into at least two subtypes characterized by how much this or that function is enhanced" (Filatova, 1999, p. 62). In other words, it is said that not less than 32 TIMs should be disti nguished.

Here we are faced with the problem that the greater the number of types and the more accurate the description of each TIM, the less reliable is the result since no test guarantees absolute accuracy. And vice versa: the smaller the number of types, the more we can be sure that we have correctly identified a person's TIM, but the description of this TIM will be of a more general rather than specific nature. 
If we continue to develop the idea proposed by E. S. Filatova, we will see that it is possible to further split up the whole set of information metabolism processes into various subtypes. The descriptions of different TIMs will become more and more accurate. Eventually, we will have something similar to a digital image, in which separate points merge into a full picture that accurately reflects the reality. However, taking into account that it is already problematic to identify a person's TIM when using the system consisting of 16 types, it will be impossible to unambiguously identify a person's TIM using a system consisting of a huge number of types the same way it is impossible to measure infinitesimals. That is, if we stick to the "principle of discreteness" (as Leonid I. Filippov called this approach to the identification of TIMs in the so-called "traditional" socionics) (Augustinavičiūtè, 2016; Bukalov, 2009), or, in other words, to the idea of fragmentation, we will find ourselves in deadlock. To overcome this obstacle, we need to go a different way and, instead of using the "principle of discreteness", return to Jung's idea that, if we take the extraversion / introversion dichotomy, "every human being possesses both mechanisms as an expression of his natural life-rhythm" (Jung, 1971), and the same is true for other psychological functions (PF), but one is "usually predominant" (Jung, 1971) while the others are "less differentiated" (Jung, 1971). This means that each person uses all 16 possible options for exchanging information with the environment. However, the possibility of using one information metabolism option is higher than that of another one. We would like to stress the word possibility, which is not the same as probability. Probability theory is based on random variables, whereas psychological phenomena are not random; they always have underlying causes even though we might not always be aware of it. At the same time, the fact that human psychology is so complex means that information metabolism processes cannot be rigidly determined. There are several possible ways in which they may develop. Moreover, information metabolism processes are inherently fuzzy. It is enough to say that the decision-making process is associated with thinking, which has been proved to have a direct connection with speech, and, consequently, is associated with verbalization and the use of linguistic variables. The fact that information is fuzzy as a substrate gives rise to the possibility of using different information metabolism options. This is why such mathematical tools as fuzzy set theory and possibility theory seem to suit the needs of socionics (Zadeh, 1978; Kaufmann, 1975).

In "traditional" socionics, there are various approaches to the problem of differences between people who seem to have the same TIM. A. V. Lustach from Belarus, a supporter of the "school of physiognomy" in socionics, writes: "The concept of subtypes as an independent classification of characters appeared in socionics after it was discovered that people who have the same TIM behave in different ways. It was first noticed in the late 1980s by the researchers who conducted socionics tests in big groups of people. As these differences could not be accounted for within the framework of the ideas about the psyche existing at that time, researchers started to develop and introduce additional classifications (subtypes, social masks, etc.) into socionics. However, their application encountered with a problem common for different directions in socionics, namely a purely behavioral approach to identifying types and describing their qualities without any connection to the structure of the psyche. Due to the fact that there are no objective criteria for identifying TIMs in socionics, different schools of socionics are yet to suggest reliable identification methods and to find where the boundaries between TIMs and subtypes lie. One and the same personal act can be explained using the idea of either the TIM or the subtype or the social mask depending on the researcher's subjective opinion. It is impossible to resolve the inconsistencies in the results of personality tests without using a reliable typological approach" (Lustach, 2009).

It should be noted that the reliability of a method used in identifying TIMs is a huge problem which has been discussed by the authors of this article (Arinicheva et al., 2008; Malishevskii et al., 2015a; Leichenko et al., 2006; Arinicheva \& Malishevskii, 2014) and such well-known supporters of the "traditional" socionics as E. S. Filatova (1999) and T. N. Prokofieva (2005). Of particular interest here is the group of bipolar characteristics which was developed and described by G. R. Reinin based on Jung's typology (Reinin, 2009). Unfortunately, discussing in 
detail the fundamental approaches proposed by T. N. Prokofieva and G. R. Reinin is beyond the scope of this article.

According to A. V. Lustach, "in the course of numerous experiments aimed at studying the behavior of people having different TIMs, Aušra Augustinavičiūtè's idea was confirmed that only one of the eight functions discovered by Jung corresponds to (and perceives) each of the eight aspects of the physical world. Also, in the course of a large number of typology experiments carried out using interviews or external characteristics, it became clear that the intensity of a person's interaction with one or another material aspect can be used to identify both the strength of a specific psychological function associated with it and its position in the structure of the psyche. This is how typology methods based on aspects / functions and the structure of the psyche were discovered. Moreover, observations showed that a person's behavior always demonstrates functions which are unusual for their TIM, which are manifested in the same way as the functions of the so-called "main" TIM, as if they were parallel. Regarding these unusual TIM functions, the person behaves in the same way as they do according to their "main" TIM. There are also eight functions which manifest themselves in the person's behavior and appearance. In other words, there are two types existing simultaneously in the psyche! A long history of observations connected with the phenomenon of the "second set of functions" gave every reason to consider this set of functions as a separate TIM that exists in the human psyche parallel to the "main" TIM. Today we can state with confidence that a person has two TIMs rather than one. And this is a norm rather than pathology because the number of people tested is measured in thousands, and all of them demonstrated having two TIMs - the main one and the additional one. Apart from the type and the subtype, there is the so-called "social mask" which is always present in human behavior. It is a model of behavior developed by the person and superimposed on the TIM and the subtype. As observations show, behavioral patterns connected with social masks are usually developed based on a person's subtype" (Lustach, 2009). These words seem to be controversial if we take them literally, but, oddly enough, if we analyze the ideas proposed by A. V. Lustach, or by the school of physiognomy, in a wider context, it becomes clear that these observations are largely consistent with our idea of the socionics model of a person.

In "traditional" socionics, the most promising are the ideas on the forms of social behavior proposed by V. V. Gulenko (2007) (DCNH system, see Figure 1).

The famous adherents of "traditional" socionics Aleksandr V. Bukalov and Olga B. Karpenko of the International Institute of Socionics (Ukraine) write in their work (Karpenko \& Bukalov, 2014): "It is inevitable that the issue of intra-type differences, or variants within a type (they are also sometimes called subtypes), emerges as soon as the principles of typology become applied in practice. Socionics distinguishes 16 types, but we observe a much greater variety of people, their characters, and kinds of stereotyped behavior in real life. One of the successful ways to describe the individual configuration of a person's psyche is using the concept of the forms of social behavior. This concept was proposed in 1991 by V. V. Gulenko (2007). As it turned out, these characteristics are a very good addition to finding a person's type in socionics as they provide for describing the behavior of a person in short-term contact at a short psychological distance. This is very important because intertype relationships manifest themselves over time. They have their own development dynamics and the nature of some of them can be reliably determined only in those pairs where people have been in regular contact for a long time. In some sense, forms of social behavior are easier to understand and present visually, especially if we observe people while they are playing a game or doing training, that is, at the very beginning of establishing interpersonal contacts. These forms are quite stable: we have been observing some people for 10-15 years and these forms have not changed. Therefore, we can assume that these characteristics correspond with some deep layers of the psyche rather than simply communication skills" (Karpenko \& Bukalov, 2014, pp. 5-6). 
V.V. Gulenko tried to formalize this difference and introduced very good terms which are opposing each other: initiating and terminating. Here is how they are defined in (Gulenko, 2007): "By terminating I mean the ability to finish what was started and a tendency toward regulation. Initiating is the opposite ability to initiate and to easily move on to something else, with an accompanying disorder in things and actions" (p. 6). The second pair of concepts introduced by V.V. Gulenko is ignoring and connecting. "The basis for this scale is assumed to be the level of sensitivity to changes in the environment. Connectors are very sensitive to such changes, whereas ignorers, as the name suggests, are capable of not paying any attention to this" (Gulenko, 2007, p. 7). At the intersection of these two axes, four forms of social behavior are found (see Figure 1).

Figure 1

Forms of social behavior (DCNH system)

according to V. V. Gulenko (2007)

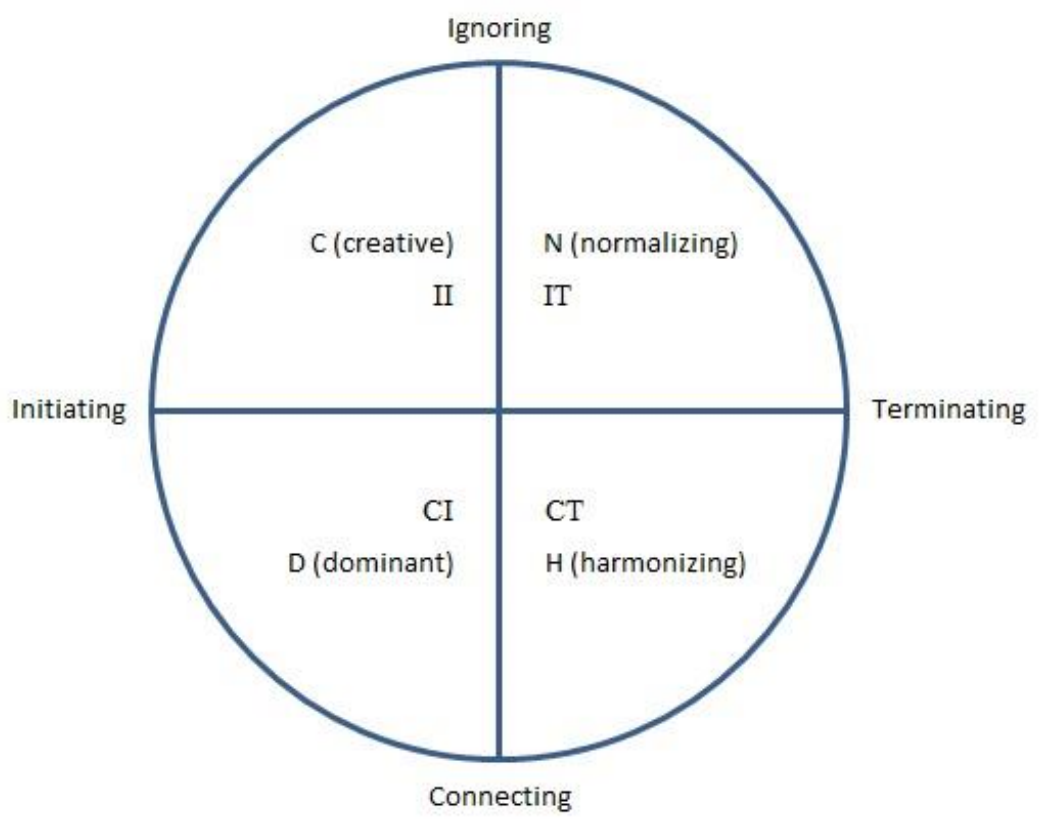

Source: Karpenko \& Bukalov (2014)

The authors of this article seem to have found the way how to deal with the fact that 16 TIMs are too simplistic and primitive for describing the huge variety of psychological processes. Based on Jung's theory, which is understood by the authors of this article in a sense very different from the understanding of this theory by Aušra Augustinavičiūte (the authors of this article do not support the so-called principle of discreteness), the authors believe that each person can manifest all 16 variants of the information metabolism process. Then, relying on the theory of fuzzy sets (Zadeh, 1978; Kaufmann, 1975), we can move on from unambiguously defined TIMs and intertype relationships to more adequate socionics models which can help to analyze information metabolism processes. The most important socionics models developed at St. Petersburg State University of Civil Aviation are the socionics model of a person (SMP) (Malishevskii et al., 2015a; Arinicheva \& Malishevskii, 2014; Leichenko et al., 2006; Leichenko, 2002) and the socionics model of intertype relationships (SMIR) (Leichenko, 2002; Leichenko et al., 2006; Arinicheva, 2008; Arinicheva et al., 2008; Arinicheva \& Malishevskii, 2014; Malishevskii et al., 2015a; Malishevskii \& Arinicheva, 2019).

Both TIM and SMP are found based on calculating data for four psychological dichotomies. The corresponding procedures are described in detail in (Malishevskii et al., 2015a; Leichenko et al., 2006). Since we are talking about linguistic variables, which, as it was mentioned earlier, are inherently fuzzy, we can only talk about the possibility that a given person may manifest one or another psychological attitude (Jung, 1971) or psychological function. Therefore, in order to develop a quantitative rather than qualitative model, it is necessary to find a 
membership function (MF) (Zadeh, 1978; Kaufmann, 1975) for each of the psychological dichotomies. It should be noted that we aim to find membership functions for psychological dichotomies as a whole rather than for one psychological function or attitude because a function and an attitude within one dichotomy are not inverse functions. (Weak extraversion with the possibility of 0.7 does not at all mean strong introversion with the possibility of 0.7 since a person can be, and most often is, ambivert or close to being ambivert). The membership function for rationality / irrationality $\left(\mu_{4}\right)$ is found as a function from logic / ethics $\left(\mu_{2}\right)$ and sensing / intuition $\left(\mu_{3}\right)$ (Leichenko et al., 2006):

$$
\mu_{4}=\mathfrak{f}\left(\mu_{2}, \mu_{3}\right)
$$

If we want to find the possibility of the simultaneous manifestation of logic and sensing in a person, the corresponding membership function will be a function of two variables rather than an algebraic product of $\mu_{2}$ and $\mu_{3}$. The possibility of this simultaneous manifestation will be determined by the area of the membership function in the corresponding quadrant. In turn, the possibility of a person manifesting a certain TIM will be determined by the four-dimensional area of the membership function found as a function of three variables in the corresponding sector, with rationality or irrationality determined by the corresponding part of this sector. Based on common sense, it follows that any membership function for any of the main dichotomies should be unimodal (Leichenko et al., 2006).

To the authors of this article, this model as a whole seems to be consistent and not contrary to common sense. However, while everything is quite simple for membership functions of individual psychological dichotomies, it is necessary to do a lot of calculations in order to use this model to assess the possibility of one particular TIM being manifested, and the results obtained will not be easy to present visually or simple to analyze. That is, this model is too complex to be used in practice. If we take into account the fact that membership functions found based on testing are far from accurate because the initial data is inaccurate, then such rigorous methodology becomes irrelevant (Leichenko et al., 2006).

Therefore, a model is needed that, on the one hand, will be quite simple, and, on the other hand, illustrative and able to, at least approximately, reflect the possibility of a particular individual manifesting one or another TIM. Such a model was developed by the authors (Leichenko et al., 2006) and used in the CRM program in Russia (Order No. 139 of the FAS Russia, 1999).

The simplest option that was originally proposed was to measure the area under the membership function graph. However, later S. D. Leichenko (2002) proposed another option: to measure the area under the graph of the $h$ function, which is found as (Leichenko et al., 2006):

$$
\mathrm{h}=\mu_{\mathrm{A}}(\mathrm{x})|\mathrm{x}-0.5|
$$

Most likely, the latter option reflects the real situation better. If we normalize the areas obtained so that the total area under the entire graph of the function is equal to unity, then the areas to the left and right of the 0.5 point can be connected with an average indicator of the possibility of an individual's manifesting this property or behavior. That is, it will be similar to mathematical expectation in probability theory (Bock et al., 2015). In this case, the average indicator of the possibility of an individual's manifesting a certain TIM can be represented as the product of the normalized areas for all four dichotomies. (For rationality / irrationality, the corresponding normalized area is calculated rather than found directly).

Then, the socionics model of a person (SMP) is a set of indicators characterizing the possibility of an individual's manifesting each of the 16 types of information metabolism.

We can also say that the SMP $\left(\mathfrak{M}_{\mathrm{SMP}}\right)$ is a projection from the set of all TIMs $(\mathfrak{I})$ into the interval $[0,1]$ 


$$
\mathfrak{M}_{\mathrm{SMP}}: \mathfrak{T} \rightarrow[0,1]
$$

where, according to a certain law, each of the 16 TIMs is connected with the possibility of its manifestation.

It should be emphasized once again that possibility (Kaufmann, 1975) is fundamentally different from probability (Bock et al., 2015). The way one or another TIM is manifested in a person is regular rather than accidental and is determined by both external conditions and the person's internal state. Therefore, if the possibility that the SLE type will be manifested in a person is 0.5 , this does not mean that in every second case his or her information metabolism processes will correspond to the dominant TIM (SLE in this case). If the external conditions are constant and the internal state is stable, then the frequency of information metabolism processes developing in accordance with the SLE type can be much higher and even close to unity. If the external conditions are highly variable, then the frequency of information metabolism processes developing in accordance with the SLE type can be much lower and close to 1/16 or even zero in situations where the external conditions actively provoke the manifestation of other TIMs which are more suitable for this situation even if they are not familiar or "convenient" for this person.

The parameters of an SMP are calculated as follows (Arinicheva et al., 2020; Malishevskii et al., 2015a; Leichenko et al., 2006):

- The initial data are the values of $\delta_{l i}, \delta_{r i}$ for each $i_{\text {th }}$ dichotomy $(i=1,2,3)$, which are the area under the graph of the $h_{i}$ function (or membership function) to the left and right of the center point (0.5), respectively.

- Then we find the normalized value of the $\delta$ areas using the following:

$$
\lambda_{\mathrm{i}}=\delta_{\mathrm{li}} /\left(\delta_{\mathrm{li}}+\delta_{\mathrm{ri}}\right), \pi_{\mathrm{i}}=\delta_{\mathrm{ri}} /\left(\delta_{\mathrm{li}}+\delta_{\mathrm{ri}}\right)
$$

- We find the values of $\lambda_{\mathrm{i}}$ and $\pi_{\mathrm{i}}$ for rationality / irrationality from the following

$$
\left\{\begin{array}{c}
\lambda_{4}=0.5+\operatorname{sign}\left(\left|0.5-\lambda_{2}\right|-\left|0.5-\lambda_{3}\right|\right) \sqrt{\left(\left|0.5-\lambda_{2}\right|-\left|0.5-\lambda_{3}\right|\right)} \\
\pi_{4}=1-\lambda_{4}
\end{array}\right.
$$

- Then we find $\mathrm{Z}_{\mathrm{m}}^{*}$, which is the degree of differentiation of each TIM in a given person (TIM numbers correspond to those accepted in socionics; see table 1), taking into account the fact that when plotting membership functions for individual dichotomies, the left part of the graph represents such qualities as extraversion $\left(\delta_{11}\right)$, logic $\left(\delta_{12}\right)$, sensing $\left(\delta_{13}\right)$ and rationality $\left(\delta_{14}\right)$ while the right part represents introversion $\left(\delta_{\mathrm{r} 1}\right)$, ethics $\left(\delta_{\mathrm{r} 2}\right)$, intuition $\left(\delta_{\mathrm{r} 3}\right)$ and irrationality $\left(\delta_{\mathrm{r}}\right)$ :

$$
\mathrm{Z}_{\mathrm{m}}^{*}=\prod_{\vartheta=1}^{4} \aleph_{\mathrm{m} \vartheta}
$$

where: $\boldsymbol{N}_{\mathrm{m} 1}=\lambda_{1}$ for $\mathrm{m}=1,3,5,7,9,11,13,15$ and $\pi_{1}$ for $\mathrm{m}=2,4,6,8,10,12,14,16$;

$\boldsymbol{\kappa}_{\mathrm{m} 2}=\lambda_{2}$ for $m=1,4,6,7,9,12,13,16$ and $\pi_{2}$ for $m=2,3,5,8,10,11,14,15$;

$\boldsymbol{\kappa}_{\mathrm{m} 3}=\lambda_{3}$ for $m=2,3,6,7,10,11,13,16$ and $\pi_{3}$ for $m=1,4,5,8,9,12,14,15$;

$\boldsymbol{N}_{\mathrm{m} 4}=\lambda_{4}$ for $m=3,4,5,6,9,10,13,14$ and $\pi_{4}$ for $m=1,2,7,8,11,12,15,16$.

A more detailed description of views presented by different schools of socionics and typology on the fact that 16 TIMs are too simplistic and primitive in describing the whole variety of information metabolism processes is impossible within the framework of this article. 


\section{Methodology}

In (Leichenko et al., 2006), the concept of the socionics model of a group (sample) (SMG) and the socionics model of a professional group (SMPG) were introduced.

The socionics model of a group is a set of indicators characterizing the possibility of the manifestation of each of the TIMs on average for this group (sample).

The socionics model of a professional group is a set of indicators characterizing the possibility of manifestation of each of the 16 TIMs in a typical representative of this professional group. The typical representative will be slightly different at different points of time since the sample, although finite at a particular moment, is variable because while some people become members of this professional group, others, on the contrary, leave it.

The difference between SMG and SMPG is qualitative rather than quantitative. SMG is simply a set of the average values of indicators characterizing the possibility of the manifestation of each of the $16 \mathrm{TIMs}\left(\mathrm{Z}_{\mathrm{m} \text { sample }}^{*}\right)$ for all members of this group (sample), which is calculated as the arithmetic mean

$$
\mathrm{Z}_{\mathrm{m} \text { sample }}^{*}=\frac{\sum_{\mathrm{k}=1}^{\mathrm{N}_{\text {sample }}} \mathrm{Z}_{\mathrm{mk}}^{*}}{\mathrm{~N}_{\text {sample }}}
$$

where $\mathrm{Z}_{\mathrm{mk}}^{*}$ is $\mathrm{Z}_{\mathrm{m}}^{*}$ of the $\mathrm{k}_{\mathrm{th}}$ member of the sample. Therefore, as a rule, there is no such $\aleph_{\mathrm{m} \vartheta}$ set that, if (2) is fulfilled, will make it possible to obtain $\mathrm{Z}_{\mathrm{m} \text { sample }}^{*}$ using expressions (3), as it happens with SMP. However, SMPG is actually the SMP of a typical representative of this professional group, and (2) and (3) are fulfilled in this case.

The fifth modification of the MM-1 test was used to test 2,857 people including students at St. Petersburg State University of Civil Aviation and the Institute of Philology, Foreign Languages and Media Communication at Irkutsk State University, flight crews from more than three dozen airlines in Russia, Azerbaijan, Belarus, Kazakhstan, Ukraine, Uzbekistan, and Estonia, air traffic controllers from almost all regions of Russia, and a number of flight attendants and representatives of transport management services who, despite the data given in (Leichenko et al., 2006), were analyzed as a separate professional group called "service", as it is difficult to classify these jobs as belonging to such areas as engineering or humanities.

The numbers of the participants were as follows: 2,356 men and 501 women. All the pilots and air traffic controllers participating in the experiment were males. Data was collected by the authors over the period from 1999 to 2019.

Using (1), (2) and (3), an SMP was found for each of them, and then an SMG was found for each professional group using (4) and taking gender into account.

A correlation analysis which included calculating the Pearson correlation coefficient (Bock et al., 2015) and conducting Pearson's chi-squared test (Bock et al., 2015) was carried out using the R programming language (Data Science and Analytics, 2020), which is widely used as statistical software for data analysis and has virtually become a standard for statistical programs. It is available under the GNU GPL license (Free Software Foundation, 2020).

The studies conducted at the premises of various airlines, air traffic control centers, St. Petersburg State University of Civil Aviation, and Irkutsk State University were carried out in accordance with the fundamental principles of bioethics (Bioethics, 2020) and on a voluntary basis. 


\section{Results}

Table 2 shows SMGs for various professional groups (\%) based on data from St. Petersburg State University of Civil Aviation (as of January 1, 2020) taking sex into account.

\section{Table 2}

Socionics models of different professional groups (\%) factoring in sex and including data from St. Petersburg University of Civil Aviation (as of January 1, 2020)

\begin{tabular}{|c|c|c|c|c|c|c|c|c|c|c|c|c|c|}
\hline \multirow{3}{*}{ 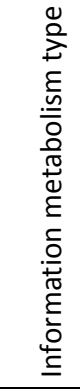 } & \multirow{3}{*}{ 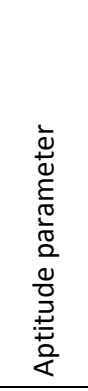 } & \multicolumn{3}{|c|}{$\begin{array}{l}\text { Flight crew } \\
\text { members }\end{array}$} & \multicolumn{3}{|c|}{$\begin{array}{l}\text { Air traffic } \\
\text { controllers }\end{array}$} & \multicolumn{2}{|c|}{$\begin{array}{c}\text { Aircraft ground } \\
\text { handling personnel }\end{array}$} & \multicolumn{2}{|c|}{$\begin{array}{c}\text { Humanities } \\
\text { majors }\end{array}$} & \multicolumn{2}{|c|}{$\begin{array}{l}\text { Transport managers } \\
\text { and flight attendants }\end{array}$} \\
\hline & & \multirow{2}{*}{ 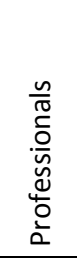 } & \multicolumn{2}{|c|}{$\begin{array}{l}\text { Civil aviation } \\
\text { students } \\
\text { (St.Petersburg) }\end{array}$} & \multirow{2}{*}{ 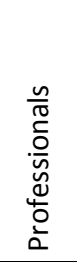 } & \multicolumn{2}{|c|}{$\begin{array}{l}\text { Civil aviation } \\
\text { students } \\
\text { (St.Petersburg) }\end{array}$} & \multirow[b]{2}{*}{$\frac{\mathscr{\varrho}}{\stackrel{\widetilde{\pi}}{\varepsilon}}$} & \multirow[b]{2}{*}{ 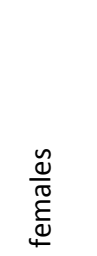 } & \multirow[b]{2}{*}{$\frac{\mathscr{U}}{\tilde{N}}$} & \multirow[b]{2}{*}{$\begin{array}{l}\frac{\mathscr{U}}{\pi} \\
\stackrel{E}{U} \\
\longleftarrow\end{array}$} & \multirow[b]{2}{*}{$\frac{\mathscr{\varrho}}{\frac{\mathscr{J}}{\varepsilon}}$} & \multirow[b]{2}{*}{$\frac{\mathscr{U}}{\frac{\mathscr{U}}{E}}$} \\
\hline & & & $\frac{\mathscr{\varrho}}{\frac{\pi}{\tilde{E}}}$ & $\frac{\mathscr{U}}{\frac{\mathscr{O}}{\mathscr{E}}}$ & & $\frac{\mathscr{\varrho}}{\stackrel{\widetilde{D}}{E}}$ & 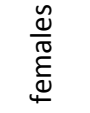 & & & & & & \\
\hline SLE & 0 & 14.9 & 14.1 & 12.8 & 12.8 & 11.3 & 13.9 & 11.6 & 12.3 & 9.6 & 9.5 & 10.4 & 11.7 \\
\hline LSE & 0 & 11.1 & 11.8 & 14.0 & 10.4 & 11.6 & 9.9 & 10.7 & 8.9 & 7.9 & 7.6 & 10.3 & 8.5 \\
\hline SLI & 0.75 & 10.0 & 8.2 & 9.2 & 9.2 & 7.0 & 8.6 & 7.8 & 7.9 & 6.8 & 5.8 & 8.3 & 8.6 \\
\hline LSI & 0.75 & 7.5 & 7.5 & 8.9 & 7.4 & 7.6 & 6.1 & 7.4 & 5.6 & 6.5 & 5.6 & 7.2 & 5.3 \\
\hline SEE & 0.75 & 8.6 & 8.6 & 7.5 & 8.4 & 7.6 & 9.6 & 7.8 & 9.8 & 7.8 & 8.7 & 7.5 & 9.7 \\
\hline LIE & 0.75 & 5.7 & 6.8 & 6.9 & 6.2 & 7.7 & 6.6 & 7.2 & 6.6 & 6.5 & 6.6 & 6.8 & 5.8 \\
\hline SEI & 1.5 & 6.0 & 5.2 & 5.2 & 6.2 & 5.1 & 6.3 & 5.3 & 6.4 & 5.7 & 5.3 & 6.4 & 7.0 \\
\hline LII & 1.5 & 4.3 & 4.4 & 4.3 & 4.6 & 5.3 & 4.2 & 5.1 & 4.1 & 5.6 & 4.8 & 5.3 & 3.7 \\
\hline ESE & 1.5 & 5.1 & 5.8 & 5.9 & 5.4 & 6.5 & 5.5 & 6.1 & 5.8 & 5.8 & 7.2 & 5.7 & 6.0 \\
\hline ILE & 1.5 & 6.3 & 6.7 & 6.1 & 6.2 & 6.1 & 6.2 & 6.4 & 6.9 & 6.6 & 7.0 & 5.7 & 6.5 \\
\hline ESI & 2.25 & 3.7 & 3.7 & 3.7 & 4.1 & 4.5 & 3.8 & 4.3 & 3.8 & 4.6 & 4.8 & 4.9 & 3.9 \\
\hline ILI & 2.25 & 4.5 & 4.0 & 4.2 & 4.7 & 4.1 & 4.5 & 4.5 & 4.6 & 5.7 & 4.5 & 4.9 & 4.8 \\
\hline IEE & 2.25 & 3.9 & 4.5 & 3.7 & 4.4 & 4.4 & 4.5 & 4.7 & 5.8 & 6.0 & 7.0 & 4.5 & 6.1 \\
\hline EIE & 2.25 & 3.1 & 3.6 & 3.1 & 3.7 & 4.7 & 3.8 & 4.6 & 4.7 & 5.4 & 6.7 & 4.3 & 5.2 \\
\hline IEI & 3 & 3.0 & 2.7 & 2.5 & 3.5 & 3.1 & 3.7 & 3.3 & 3.9 & 5.2 & 4.4 & 4.0 & 4.2 \\
\hline Ell & 3 & 2.3 & 2.4 & 2.0 & 2.8 & 3.4 & 2.8 & 3.2 & 2.9 & 4.3 & 4.5 & 3.8 & 3.0 \\
\hline \multicolumn{2}{|c|}{ TOTAL (people) } & 803 & 455 & 23 & 541 & 103 & 36 & 286 & 96 & 63 & 273 & 105 & 73 \\
\hline \multicolumn{2}{|c|}{$\xi \geq 1.5$} & 42.2 & 43 & 40.7 & 45.6 & 47.2 & 45.3 & 47.5 & 48.9 & 54.9 & 56.2 & 49.5 & 50.4 \\
\hline \multicolumn{2}{|c|}{$\xi>1.5$} & 20.5 & 20.9 & 19.2 & 23.2 & 24.2 & 23.1 & 24.6 & 25.7 & 31.2 & 31.9 & 26.4 & 27.2 \\
\hline \multicolumn{2}{|c|}{$\xi>2.25$} & 5.3 & 5.1 & 4.5 & 6.3 & 6.5 & 6.5 & 6.5 & 6.8 & 9.5 & 8.9 & 7.8 & 7.2 \\
\hline
\end{tabular}

Source: Own elaboration based on research results

If we compare different samples shown in table 2, it can be seen that logic and sensing aspects are predominant in the model even if we take the so-called humanities sector. Perhaps this can be explained by the fact that the Russian population has certain characteristics ((Leichenko et al., 2006) contains data on the characteristics of TIM distribution in the US population and differences from a similar distribution in the UK). However, it is most likely a consequence of the fact that the majority of the data was collected from air transport professionals. The "humanities" sector covers 336 participants, 214 of which were students studying humanities at St. Petersburg State University of Civil Aviation and 122 of which were students at Irkutsk State University.

The socionics portrait of a group (SPG) is a distribution of the predominant components of the SMP (TIM) in a particular sample (Malishevskii et al., 2015a; Leichenko et al., 2006). SPGs of the professional groups we are discussing are given in table 3. 
Table 3

Socionics portraits of samples representing different professional groups factoring in sex and including data from St. Petersburg University of Civil Aviation (as of January 1, 2020)

\begin{tabular}{|c|c|c|c|c|c|c|c|c|c|c|c|c|c|c|}
\hline \multirow{3}{*}{ 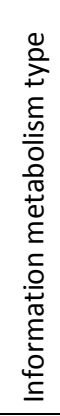 } & \multirow{3}{*}{ 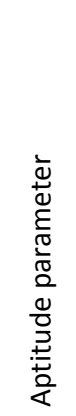 } & \multicolumn{3}{|c|}{$\begin{array}{c}\text { Flight } \\
\text { crew } \\
\text { members }\end{array}$} & \multicolumn{3}{|c|}{$\begin{array}{c}\text { Air } \\
\text { traffic } \\
\text { controllers }\end{array}$} & \multicolumn{2}{|c|}{$\begin{array}{l}\text { Aircraft ground } \\
\text { handling } \\
\text { personnel }\end{array}$} & \multicolumn{2}{|c|}{$\begin{array}{c}\text { Humanities } \\
\text { majors }\end{array}$} & \multicolumn{2}{|c|}{$\begin{array}{l}\text { Transport } \\
\text { managers and } \\
\text { flight } \\
\text { attendants }\end{array}$} & \multirow[b]{3}{*}{$\underset{1}{\frac{1}{5}}$} \\
\hline & & \multirow{2}{*}{ 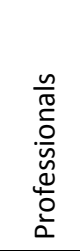 } & \multicolumn{2}{|c|}{$\begin{array}{l}\text { Civil aviation } \\
\text { students } \\
\text { (St.Petersburg) }\end{array}$} & \multirow{2}{*}{$\begin{array}{l}\frac{n}{N} \\
\frac{0}{c} \\
\frac{0}{\tilde{N}} \\
\tilde{U} \\
\frac{0}{0} \\
\frac{0}{0}\end{array}$} & \multicolumn{2}{|c|}{$\begin{array}{l}\text { Civil aviation } \\
\text { students } \\
\text { (St.Petersburg) }\end{array}$} & \multirow[b]{2}{*}{$\frac{\mathscr{\varrho}}{\mathscr{\Xi}}$} & \multirow[b]{2}{*}{$\frac{\mathscr{U}}{\frac{\mathscr{U}}{\sqrt[T]{C}}}$} & \multirow[b]{2}{*}{$\frac{\mathscr{\varrho}}{\frac{\tilde{N}}{\varepsilon}}$} & \multirow[b]{2}{*}{ 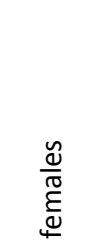 } & \multirow[b]{2}{*}{$\frac{\tilde{\mathscr{U}}}{\tilde{\mathscr{E}}}$} & \multirow[b]{2}{*}{ 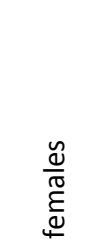 } & \\
\hline & & & $\frac{\tilde{\varrho}}{\tilde{\varepsilon}}$ & 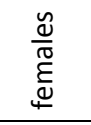 & & $\frac{\mathscr{\varrho}}{\frac{\tilde{U}}{\tilde{E}}}$ & 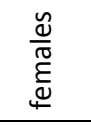 & & & & & & & \\
\hline SLE & 0 & 319 & 184 & 8 & 182 & 31 & 15 & 85 & 23 & 11 & 55 & 26 & 21 & 960 \\
\hline LSE & 0 & 201 & 143 & 8 & 133 & 36 & 12 & 76 & 16 & 8 & 30 & 29 & 10 & 702 \\
\hline SLI & 0.75 & 121 & 38 & 3 & 74 & 7 & 3 & 30 & 14 & 5 & 11 & 11 & 11 & 328 \\
\hline LSI & 0.75 & 81 & 47 & 3 & 57 & 13 & 1 & 29 & 9 & 6 & 15 & 11 & 4 & 276 \\
\hline SEE & 0.75 & 30 & 15 & 1 & 25 & 7 & 1 & 17 & 10 & 5 & 30 & 8 & 9 & 158 \\
\hline LIE & 0.75 & 5 & 3 & 0 & 8 & 3 & 1 & 15 & 6 & 6 & 15 & 3 & 0 & 65 \\
\hline SEI & 1.5 & 12 & 5 & 0 & 17 & 1 & 1 & 2 & 5 & 2 & 9 & 8 & 4 & 66 \\
\hline LII & 1.5 & 9 & 3 & 0 & 6 & 1 & 0 & 5 & 1 & 2 & 9 & 1 & 0 & 37 \\
\hline ESE & 1.5 & 3 & 4 & 0 & 5 & 0 & 0 & 5 & 2 & 2 & 17 & 1 & 3 & 42 \\
\hline ILE & 1.5 & 5 & 1 & 0 & 5 & 0 & 0 & 3 & 2 & 1 & 9 & 0 & 1 & 27 \\
\hline ESI & 2.25 & 2 & 1 & 0 & 3 & 0 & 1 & 1 & 0 & 1 & 10 & 2 & 2 & 23 \\
\hline ILI & 2.25 & 5 & 3 & 0 & 3 & 0 & 0 & 6 & 0 & 3 & 4 & 2 & 0 & 26 \\
\hline IEE & 2.25 & 2 & 3 & 0 & 3 & 1 & 0 & 2 & 3 & 3 & 18 & 0 & 2 & 37 \\
\hline EIE & 2.25 & 3 & 3 & 0 & 7 & 1 & 0 & 6 & 5 & 5 & 23 & 1 & 4 & 58 \\
\hline $\mathrm{IEI}$ & 3 & 2 & 1 & 0 & 10 & 0 & 1 & 3 & 0 & 3 & 9 & 0 & 1 & 30 \\
\hline EII & 3 & 3 & 1 & 0 & 3 & 2 & 0 & 1 & 0 & 0 & 9 & 2 & 1 & 22 \\
\hline \multicolumn{2}{|c|}{ Total } & 803 & 455 & 23 & 541 & 103 & 36 & 286 & 96 & 63 & 273 & 105 & 73 & 2.857 \\
\hline \multicolumn{2}{|c|}{$\xi \geq 1.5$} & $5.7 \%$ & $5.5 \%$ & $0.0 \%$ & $11.5 \%$ & $5.8 \%$ & $8.3 \%$ & $11.9 \%$ & $18.8 \%$ & $34.9 \%$ & $42.9 \%$ & $16.2 \%$ & $24.7 \%$ & $12.9 \%$ \\
\hline \multicolumn{2}{|c|}{$\xi>1.5$} & $2.1 \%$ & $2.6 \%$ & $0.0 \%$ & $5.4 \%$ & $3.9 \%$ & $5.5 \%$ & $6.6 \%$ & $8.3 \%$ & $23.8 \%$ & $26.7 \%$ & $6.7 \%$ & $13.7 \%$ & $6.7 \%$ \\
\hline \multicolumn{2}{|c|}{$\xi>2.25$} & $0.6 \%$ & $0.4 \%$ & $0.0 \%$ & $2.4 \%$ & $1.9 \%$ & $2.8 \%$ & $1.4 \%$ & $0.0 \%$ & $4.8 \%$ & $6.6 \%$ & $1.9 \%$ & $2.7 \%$ & $1.8 \%$ \\
\hline
\end{tabular}

In contrast to table 3, what makes table 2 striking is similarities between SMGs rather than differences which can be seen between SPGs. These similarities can be seen even better in table 4, which shows the correlations found between SMGs. Almost all of them, except for two, are strong correlations (Bock et al., 2015). All moderate correlations (Bock et al., 2015) are correlations between the SMG of females in humanities and a number of other SMGs. Moreover, they are all, except for four, highly significant $(p<0.001)$. This might seem very strange, but the authors of this article are inclined to believe that these facts can be explained by mentality factors. 
Table 4

Correlations found between different professional groups factoring in sex and including data from St. Petersburg University of Civil Aviation (as of January 1, 2020)

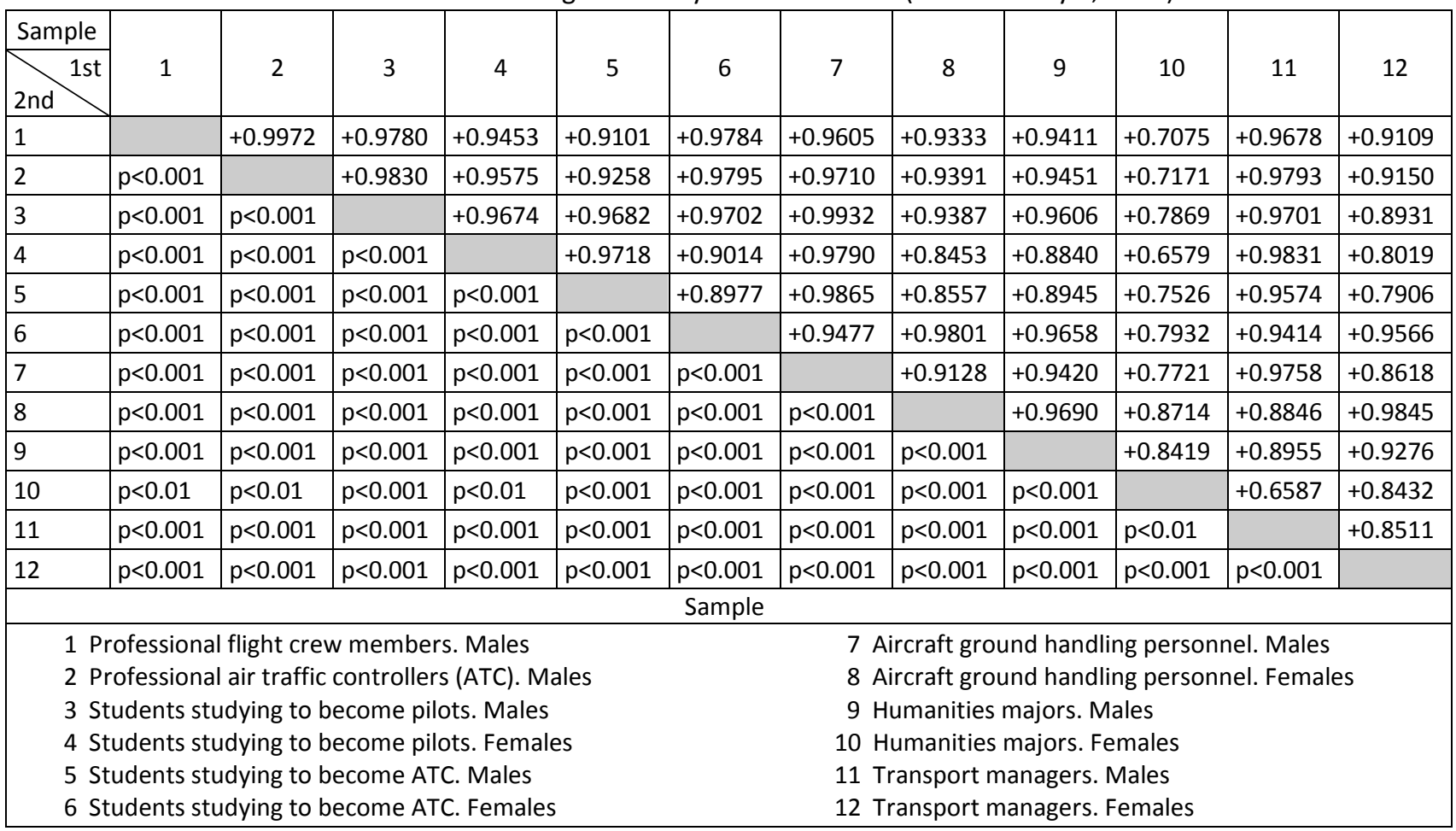

Note: on the right and at the top of the table, the results of Pearson' chi-squared test are given; on the left and at the bottom of the table, correlation significance values are given (Bock et al., 2015) Source: Own elaboration based on research results

When analyzing SPGs, a highly significant difference $(p<0.01)$ using Pearson's chi-squared test (Bock et al., 2015) was found between pilots and air traffic controllers; the closest correlation of all those shown in table 4 is observed between their SMGs $\left(r_{\text {corr. }}=0.9972\right)$. This seems to be very close to reality due to similar requirements for representatives of these professions and, accordingly, psychological screening methods. This makes the fact that there are highly significant differences between the samples of their TIMs to be more likely a fluctuation rather than a trend, especially taking into account the absence of significant differences between these groups discussed in (Leichenko et al., 2006; Malishevskii et al., 2005).

As similar results were obtained using a sample of 2,394 people and discussed in (Malishevskii et al., 2015a), it was said that it was difficult to explain why tables 2 and 4 showed such a picture. It was said that data should be collected from students who study "real" humanities. The reason why it was said so was that students studying humanities at St. Petersburg State University of Civil Aviation are quite "specific". Therefore, with the active assistance of the freelance psychologist V. S. Kamenskaya, data was collected on the socionics characteristics of students studying at Irkutsk State University and majoring in foreign studies and translation studies, i.e. the areas which are far from the air transport industry. The results were very interesting. Since, for obvious reasons, there were few male students studying humanities, samples of female students were studied first of all. As can be seen from table 5, the sample of students studying humanities at St. Petersburg State University of Civil Aviation indeed differs from the sample of students studying humanities at Irkutsk State University in that it is much closer in its socionics characteristics to people whose TIMs suit the tasks performed by air traffic controllers. (The parameter $\xi$ showing career aptitude in aviation which was proposed in (Leichenko, 2002; Leichenko et al., 2006; Arinicheva, 2008) varies from $\xi=0$ - completely fit, to $\xi=3$ - obviously unfit). 
Table 5

The share of females studying humanities (\%)

in different SMGs and unfit for aviation

\begin{tabular}{|c|c|c|c|}
\hline & $\begin{array}{c}\text { Female students in St. Petersburg } \\
\text { (180 people) }\end{array}$ & $\begin{array}{c}\text { Female students in Irkutsk } \\
\text { (93 people) }\end{array}$ & $\begin{array}{c}\text { Total } \\
\text { (273 people) }\end{array}$ \\
\hline$\xi \geq 1.5$ & 54.6 & 59.32 & 54.9 \\
\hline$\xi>1.5$ & 30.5 & 34.52 & 31.2 \\
\hline$\xi>2.25$ & 7.5 & 11.67 & 9.5 \\
\hline
\end{tabular}

Source: Own elaboration based on research results

Table 6 shows a comparison between the distributions of TIMs among female students studying humanities at St. Petersburg State University of Civil Aviation from (Malishevskii et al., 2015a) and female students studying humanities at Irkutsk State University using Pearson's chi-squared test. The differences are highly significant ( $p \leq$ 0.01).

Table 6

A comparison between the distributions of TIMs among female students studying humanities at St.Petersburg State University of Civil Aviation and female students studying humanities at Irkutsk State University using Pearson's chi-squared test

\begin{tabular}{|c|c|c|c|c|c|c|c|c|}
\hline $1^{\text {st }}$ sample & $\mathrm{N}_{1}$ & $2^{\text {nd }}$ sample & $\mathrm{N}_{2}$ & \multicolumn{2}{|c|}{$\begin{array}{c}\text { Degrees of freedom, } \\
v\end{array}$} & $\chi^{2}$ emp. & $\chi^{2}$ cr. & Conclusion \\
\hline $\begin{array}{c}\text { Female students } \\
\text { studying humanities } \\
\text { in Irkutsk }\end{array}$ & 93 & $\begin{array}{c}\text { Female students } \\
\text { studying humanities } \\
\text { in St.Petersburg }\end{array}$ & 180 & \multicolumn{2}{|c|}{9} & 49.076 & $\begin{array}{l}16.919 \text { for } p<0.05 \\
21.666 \text { for } p<0.01\end{array}$ & $\begin{array}{c}\text { Differences are } \\
\text { highly significant } \\
(p \leq 0.01)\end{array}$ \\
\hline & & \multicolumn{3}{|c|}{$\begin{array}{l}\text { Female students studying humanities } \\
\text { in Irkutsk }\end{array}$} & \multicolumn{3}{|c|}{$\begin{array}{l}\text { Female students studying humanities } \\
\text { in St.Petersburg }\end{array}$} & $\mathrm{R}$ \\
\hline SLE & & \multicolumn{3}{|l|}{14} & \multicolumn{3}{|c|}{41} & 1.8158 \\
\hline LSE & & \multicolumn{3}{|l|}{5} & \multicolumn{3}{|c|}{25} & 4.0435 \\
\hline $\mathrm{SLI}+\mathrm{LSI}$ & & \multicolumn{3}{|l|}{17} & \multicolumn{3}{|c|}{9} & 11.3540 \\
\hline SEE & & \multicolumn{3}{|l|}{8} & \multicolumn{3}{|c|}{22} & 0.7313 \\
\hline LIE & & \multicolumn{3}{|l|}{5} & \multicolumn{3}{|c|}{10} & 0.0036 \\
\hline ESE & & \multicolumn{3}{|l|}{2} & \multicolumn{3}{|c|}{15} & 3.7642 \\
\hline SEI + LII + ILE & & \multicolumn{3}{|l|}{12} & \multicolumn{3}{|c|}{15} & 10.0957 \\
\hline IEE & & \multicolumn{3}{|l|}{3} & \multicolumn{3}{|c|}{15} & 2.4261 \\
\hline EIE & & \multicolumn{3}{|l|}{6} & \multicolumn{3}{|c|}{17} & 0.6519 \\
\hline \multicolumn{2}{|l|}{$\mathrm{ESI}+\mathrm{ILI}+\mathrm{IEI}+\mathrm{EII}$} & \multicolumn{3}{|l|}{21} & \multicolumn{3}{|c|}{11} & 14.1895 \\
\hline \multicolumn{2}{|l|}{$\chi^{2}$ emp. } & \multicolumn{3}{|l|}{93} & \multicolumn{3}{|c|}{180} & 49.0756 \\
\hline
\end{tabular}

Source: Own elaboration based on research results

Of course, as can be seen from table 6, there are obvious differences concerning the distribution of SLI and LSI types, which are prominent in the sample of female students studying in Irkutsk, but the most significant difference is in the numbers of the representatives of ESI, ILI, IEI, and Ell types, which are considered to be unfit for aviation.

At the same time, $r_{\text {CORR }}=+0.6437$ with high significance $(p<0.01)$ was obtained for SMGs of pilots (Malishevskii et al., 2015a) and females studying humanities in Irkutsk, while $r_{\text {CORR }}=-0.0524$ with insignificant $(p \geq 0.05)$ and negative (!) correlation was obtained for SMGs of the two samples of females studying humanities at two different universities. This suggests that despite all the differences between the SPGs and SMGs of professional male pilots and females studying humanities, there are certain patterns connected with mentality. At the same time, in the samples that are in general similar to each other, differences rather than similarities and trends begin to play the role. 


\section{Conclusions}

Correct psychological screening procedures that pilots and air traffic controllers undergo play an important role in reducing the negative impact of the human factor on flight safety (Malishevskii et al., 2015b).

Socionics characteristics, including the SMP of an operator, influence how the person handles information flows and, as a result, are relevant at work and should be taken into account when conducting professional screening.

It seems safe to say that mentality plays an important role in the development of a person's socionics characteristics.

Despite strong correlations between SMGs, the differences are quite obvious. For example, the possibility that students of both sexes studying humanities will manifest TIMs that are unfit for aviation is $10 \%$ higher than among professional pilots. That is, socionics models of professional groups do exist, as do socionics portraits of professional groups. However, it is necessary to collect and analyze more data in order to get more accurate results.

Based on table 2, the first version of the SMPG of professional pilots was developed, which is presented in table 7. It takes into account the relationships within dichotomies that are present in the corresponding SMG while meeting the conditions (2) and (3), that is, the SMPG is calculated based on (3) as an SMP, provided that $\lambda_{1}=0.6$, $\pi_{1}=0.4, \lambda_{2}=0.65, \pi_{2}=0.35, \lambda_{3}=0.66, \pi_{3}=0.34$ and, accordingly, based on (2) $-\lambda_{4}=0.4, \pi_{4}=0.6$.

The ways how SMPs can be applied in practice have been discussed in a number of works, including (Mukhtarov et al., 1999; Lejchenko et al., 2002; Leichenko, 2002; Paşayev et al., 2005; Leichenko et al., 2006; Arinicheva, 2008).

Table 7

A socionics model of the professional group "Flight crew members (professionals)" based on the corresponding SMG (in \%)

\begin{tabular}{|c|c|c|c|c|c|c|c|}
\hline ILE & SEI & ESE & LII & EIE & LSI & SLE & IEI \\
\hline 7.9 & 5.5 & 5.6 & 3.6 & 2.9 & 6.9 & 15.4 & 2.9 \\
\hline LIE & ESI & SEE & ILI & LSE & EII & IEE & SLI \\
\hline 5.3 & 3.7 & 8.3 & 5.3 & 10.3 & 1.9 & 4.3 & 10.3 \\
\hline
\end{tabular}

Source: Own elaboration based on research results

An interesting option for the use of SMPs was proposed at Kirovograd Flight Academy (National Aviation University, Ukraine). The authors of (Kharchenko et al., 2012) write: "Based on the MM-1 questionnaire, an automated module called SMP Diagnostics was created to analyze the socionics characteristics of aviation professionals, which is used in a training system in order to implement a customized approach to teaching that takes into account a cadet's type of personality. The computer program was developed using the high-level Object Pascal language and the Inprise Delphi 7 environment. Using the automated module, we study how well operators interact while performing professional tasks in special cases" (p. 20).

The issue of improving flight safety, which can be solved using such tools as socionics characteristics, is quite compatible with those issues concerning improving flight safety that were considered by the authors of this article in (Arinicheva et al., 2008; Dzhapharadze \& Malishevsky, 2013; Malishevskii et al., 2015a; Smurov et al., 2017; Arinicheva et al., 2018; Arinicheva \& Malishevskii, 2019a; Arinicheva \& Malishevskii, 2019b; Arinicheva et al., 2019; Malishevskii \& Arinicheva, 2019) and a number of others. 


\section{Bibliographic references}

Arinicheva, O. V. (2008). Improving the methods of managing human resources in the crew-aircraft system by reducing the negative impact of the human factor on flight safety. PhD Dissertation. St.Petersburg.

Arinicheva, O. V., \& Malishevskii, A. V. (2014). Psychodiagnostics - one of the tools of aircraft crew resource management. Civil Aviation High Technologies, 1(199), 117-125.

Arinicheva, O. V., \& Malishevskii, A. V. (2017). Back to Jung: are the authors of this article socionics? Socionics, Mentology and Personality Psychology, 2(131), 42-51.

Arinicheva, O. V., \& Malishevskii, A. V. (2019a). Improving the reliability of professional psychological selection of aviation specialists. Dependability, 19(1), 40-47.

Arinicheva, O. V., \& Malishevskii, A. V. (2019b). Some aspects of prevention of conflict behaviour in the aircraft crew. Transport: Science, Equipment, Management(10), 27-34.

Arinicheva, O. V., Kovalenko, G. V., Malishevskii, A. V., Parfenov, I. A., \& Petrova, M. V. (2008). Application of socionics models in feasibility studies of air transport management methods. All-Russian ScientificTechnical Journal "Polyot"(1), 45-49.

Arinicheva, O. V., Lebedeva, N. A., \& Malishevskii, A. V. (2019). Intellectual functioning in students and conflict management strategies. Revista Espacios, 40(44), 29. Retrieved from: http://www.revistaespacios.com/a19v40n44/19404429.html

Arinicheva, O. V., Lebedeva, N. A., \& Malishevskii, A. V. (2020). Socionics aspects of the human factor in aviation. Revista Espacios, 41(21), 391-407. Retrieved from: http://www.revistaespacios.com/a20v41n21/20412130.html

Arinicheva, O., Dalinger, Y., Malishevskii, A., Sukhikh, N., \& Khoroshavtsev, Y. (2018). Objectification of subjective estimation of abnormal cases danger in air traffic control. Transport Problems, 13(1), 5-18.

Augustinavičiūtė, A. (2016). Socionics. Moscow: Black Squirrel Publishing Group.

Bioethics. (2020). Retrieved from https://www.iep.utm.edu/bioethic/

Blutner, R., \& Hochnadel, E. (2010). Two qubits for C.G. Jung's theory of personality. Cognitive Systems Research, 11(3), 243-259.

Bock, D. E., Velleman, P. F., \& De Veaux, R. D. (2015). Stats: modeling the world. Boston: Pearson Addison Wesley.

Bukalov, A. V. (2003). On the difference between socionics and Myers-Briggs typology. Socionics, Mentology and Personality Psychology, 6(51), 62-64.

Bukalov, A. V. (2009). The potential of a person and the mysteries of human relationships. Moscow: Black Squirrel Publishing Group.

Bukalov, A. V. (2017). On the article "Back to Jung: are the authors of this article socionics?" by O.V. Arinicheva and A.V. Malishevskii. Socionics, Mentology and Personality Psychology, 2(131), 52-59.

Data Science and Analytics. (2020). Retrieved from http://it.unt.edu/research 
Dzhapharadze, T. R., \& Malishevsky, A. V. (2013). The challenge of improving professional psychological selection of pilots of civil aviation. Medico-Biological and Socio-Psychological Problems of Safety in Emergency Situations(3), 66-70.

Filatova, E. S. (1999). Socionics for everyone. The science of communication, understanding, and agreement. St.Petersburg: B\&K.

Free Software Foundation. (2020). Retrieved from https://fsf.org/

Gulenko, V. V. (2007). The theory of subtypes: system DCNH. Socionics, Mentology and Personality Psychology, $6(75), 5-15$.

Jung, C. G. (1971). Psychological Types. Princeton: Princeton University Press.

Karpenko, O., \& Bukalov, A. (2014). DCNH system in socionic consulting. Socionics, Mentology and Personality Psychology, 2(113), 5-16.

Kaufmann, A. (1975). Introduction à la théorie des sous-ensembles flous à l'usage des ingénieurs: applications à la linguistique, à la logique et à la sémantiqu. Paris, New-York, Barcelone, Milan: Masson.

Keirsey, D. (1998). Please Understand Me II: Temperament, Character, Intelligence. Del Mar, CA: Prometheus Nemesis Book Company.

Kępiński, A. (2014). Melancholia. Kraków: Wydawnictwo Literackie.

Kharchenko, V. P., Shmeleva, T. F., Sikirda, Y. V., \& Zemlyanskiy, A. V. (2012). Application of socionics methods for completing the professionals' groups of air navigation systems. Proceedings of the National Aviation University, 1(50), 14-21.

Leichenko, S. D. (2002). Development of a model for building aircraft crews aimed at improving flight safety. PhD Dissertation. St.Petersburg.

Leichenko, S. D., Malishevskii, A. V., \& Mikhailik, N. F. (2006). Human factor in aviation. (Vol. 2). St.Petersburg: State University of Civil Aviation \& Kirovograd: State Flight Academy of Ukraine.

Lejchenko, S. D., Malishevskij, A. V., \& Mikhajlik, N. F. (2002, May 27). Patent No. 2182815. Method for evaluating aircraft crew training quality in the human factor sphere. Russian Federation. Retrieved from: https://www.elibrary.ru/item.asp?id=3

Lustach, A. V. (2009). Subtypes: temperaments and social masks in socionics. Retrieved from http://psychotype.ru/article/a-39.html

Malishevskii, A. V., \& Arinicheva, O. V. (2019). Prognostic criterion of effectiveness of crewmember interaction. World of Transport and Transportation, 1(80), 204-214. Retrieved from: https://mirtr.elpub.ru/jour/article/view/1620/1938

Malishevskii, A. V., Arinicheva, O. V., \& Kaymakova, E. M. (2015a). Socionic modelling of professional employees' groups in air transport. Transport: Science, Equipment, Management(4), 13-20.

Malishevskii, A. V., Grigorjev, G. I., \& Leichenko, S. D. (2005). A problem of development of professional psychological selection of the aviation personnel. Bulletin of Psychotherapy, 14(19), 58-75. 
Malishevskii, A. V., Vlasov, E. V., \& Kajmakova, E. M. (2015b). Possible ways to reduce the negative impact of human factor in transport emergencies. Medico-Biological and Socio-Psychological Problems of Safety in Emergency Situations(1), 108-114.

Mukhtarov, M. A., Malishevskij, A. V., \& Mikhajlik, N. F. (1999, April 10). Patent No. 2128471. Method for assessing efficiency of interaction in aircraft crew. Russian Federation. Retrieved from: https://www.elibrary.ru/item.asp?id=38124138

Myers, I. B., \& McCaulley, M. H. (1985). Manual: A guide to the development and use of the Myers Briggs Type Indicator. Palo Alto, CA: Consulting Psychologists Press.

Myers, I. B., \& Myers, P. B. (1995). Gifts Differing: Understanding Personality Type. Mountain View, CA: DaviesBlack Publishing.

Order No.139 of the FAS Russia. (1999). On the introduction of training programs involving the human factor for civil aviation crew members in the Russian Federation (CRM Russia).

Paşayev, A. M., Cəfərzadə, R. M., Məmmədov, A. M., Mixaylik, N. F., \& Malişevskiy, A. V. (2005, January 05). Patent No. 2005 0071. İnsan amili sahəsində uçuş heyətinin peşə hazirlı̆̆ı üsulu. Azərbaycan Respublikası.

Prokofieva, T. N. (2005). Algebra and geometry of human relationships. St.Petersburg: Diamond Publishing House.

Reinin, G. R. (2009). The secrets of the type. Models. Groups. Signs. Moscow: Black Squirrel Publishing Group.

Smurov, M. Y., Arinicheva, O. V., Kovalenko, G. V., Balyasnikov, V. V., \& Chepiga, V. E. (2017). Possible solutions to reduce the negative impact of human factors on flight safety. Jr. of Industrial Pollution Control, 33(1), 1195-1201.

Zadeh, L. A. (1978). Fuzzy sets as a basis for a theory of possibility. Fuzzy sets and Systems(1), 3-28.

Esta obra está bajo una Licencia Creative Commons

Attribución-NoCommercial 4.0 International

\section{(cc) BY-NC}

